\title{
THE DETERMINATION OF PARAMETERS OF MULTI-STEP ADSORPTION ISOTHERM BY SEQUENTIAL SIMPLEX OPTIMIZATION
}

\author{
L. TOLNER \\ Department for Soil Science and Agricultural Chemistry, Szent István University \\ Pater Karoly street, H-2103 Gödöllö, Hungary \\ (phone: +36-30-581-0327; fax: +36-28-522-081) \\ *Corresponding author \\ e-mail: tolner.laszlo@gmail.com \\ (Received $25^{\text {th }}$ October 2008 ; accepted $13^{\text {rd }}$ December 2008)
}

\begin{abstract}
The nutrient and toxic compounds can be adsorbed on the surface of soil colloids. Investigating the adsorption of some pesticide compounds, instead of the simply asymptotic Langmuir isotherm multistep isotherms can be obtained. In these cases a new layer is formed after the surface saturation, however, this mechanism can be described by using a new Langmuir-type isotherm. The adsorption of some compounds led to three superposition steps. The mathematical form is a nonlinear function with 8 parameters. The parameters were determined by a robust, direct optimum searching subroutine carried out by Visual basic macro made in Excel spreadsheet program which uses a simplex stepping procedure. The aim of the optimization is to minimize the residual sum of squares between measured and calculated values. The aim function can be calculated for any parameter series in the adequate dimension number. During the iteration the residual sum of squares decreases step by step, while the differences will be negligible.
\end{abstract}

Keywords: Regression; model; adsorption; pesticide; soil

\section{Introduction}

The sorption on the solid matrix of the soil is one of the most important processes which control transport, persistence, bioavailability and degradation of organic pesticides on soil.

Many theories and models have been presented in the literature to describe the different types of sorption isotherms (Sposito 1984, Sparks 1999). Derivation of a scientifically based adsorption isotherm was first achieved by Langmuir (1918). The Langmuir isotherm model assumes monolayer adsorption on an energetically homogeneous surface, where the adsorption takes place only at specific localized sites and the saturation coverage corresponds to complete occupancy of these sites. Each site can accommodate only one molecule or atom and there is no interaction between neighbouring adsorbed molecules or atoms. Several more complex equations such as that of Brunauer, Emmett, and Teller (BET isotherm) have been proposed for multilayer adsorption (Brunauer 1938). Gregg and Sing have given a detailed discussion of the various models used to interpret each type of the isotherms (Greg, 1982). The most commonly used adsorption isotherm equations for organic contaminant on soil are the Langmuir and the Freundlich isotherms. In many cases the sorption of pesticides has been well described using these empirical models (Sparks 1993). These commonly used equations have the advantage of the possibility of linearization giving the adsorption parameters by the slope and intercept of the fitted line. These equations have been found to fit the adsorption data of some pesticide moderately well and have occasionally been 
used to estimate the capacity for adsorption. Using more realistic assumptions, modifications have been made to the Langmuir isotherm, which are summarized in the monographs of Ruthven (1984), Yang (1987), Adamson (1990), Rudzinski and Everett (1992).

Czinkota et al. (2002) derived a non-linear mathematical model - obtained from geometric series of modified Langmuir equation with the additional assumption that the actual location of the surface sites are covered either by one or more than one molecule, in the form of associated complex. Such complexes may result, for example, from the dispersion forces acting between the hydrophobic surfaces of the dissolved molecules. They assume formation of layers of associated complexes of different composition characterized by the association number $(n)$, beginning with a single layer of the solute, continued with the layer of dimers $(n=2)$, trimers $(n=3)$ etc. The physicochemical interpretation of the theory is detailed below.

The following chemical equation means that the sorbent - soil in this case - can adsorb one or more than one molecule in form of associated complexes on its surface.

where

$$
e+n c=q
$$

$e \quad$ the possible maximum concentration of the substance on an empty surface area per unit mass $[\mathrm{mg} / \mathrm{kg}]$

$c$ the concentration of the dissolved, non associated substance in solution[mg/L]

$q$ the concentration of the substance on the covered area (occupied site) $[\mathrm{mg} / \mathrm{kg}]-$ specific adsorbed amount

$n$ it is an integer, representing the degree of molecular association (association number)

The equilibrium constant of the reaction in (Eq.1):

$$
k=\frac{q}{e \cdot c^{n}}
$$

where

$k \quad$ the equilibrium constant $\left[(1 / \mathrm{mg})^{\mathrm{n}}\right]$

If the adsorption area is finite, the following balance equation describes that the sum of the empty and covered area equal to total adsorption area:

$a=e+q, \quad$ in other form $e=a-q$

where

$a$ the total adsorption capacity $[\mathrm{mg} / \mathrm{kg}]$

We can use this function for describing the chemical equilibrium, in the following form:

$$
k=\frac{q}{(a-q) \cdot c^{n}}
$$

which after appropriate transformations, yields:

$$
q=\frac{a \cdot k \cdot c^{n}}{1+k \cdot c^{n}}
$$

The calculation above is similar to the derivation of original Langmuir isotherm, the difference is just in the number of bounded molecules, and in the equation $n$ power number. Furthermore, a critical concentration of the substance on the surface depending on the adsorbate-surface interaction is assumed. Above this concentration, formation of a new adsorbed layer with different association number could be considered. In order to have good biological efficiency most of the pesticides consist of functional groups with 
different hydrophobic character. These compounds, however, may form associates on the surface or in the solution. Using the limit concentration, the equation (Eq. 4) can be modified in the following way:

$$
q=\frac{a \cdot k \cdot(c-b)^{n}}{1+k \cdot(c-b)^{n}}
$$

where

$b$ the concentration limit of associated compounds [mg/L]

In a physical approach, the function can be used only if $c>b$. Thus the equation must be modified using a new function, which equals to zero if the concentration of original compound is less than the critical concentration and in a higher concentration interval it is in linear function of the original compound concentration.

$$
\begin{array}{ll}
{\left[\frac{(c-b)+a b s(c-b)}{2}\right]=c-b,} & \\
{\left[\frac{(c-b)+a b s(c-b)}{2}\right]=0,} & \text { if } c-b>0, \text { and } \\
& \text { if } c-b \leq 0
\end{array}
$$

Thus the (Eq.5) could be rewritten:

$$
q=\frac{a \cdot k \cdot\left[\frac{(c-b)+a b s(c-b)}{2}\right]^{n}}{1+k \cdot\left[\frac{(c-b)+a b s(c-b)}{2}\right]^{n}}
$$

After transformation (Eq.6) yields:

$$
q=\frac{a \cdot k \cdot[(c-b)+a b s(c-b)]^{n}}{2^{n}+k \cdot[(c-b)+a b s(c-b)]^{n}}
$$

This mathematical formula describes the model of one step for any associates (any $n)$.

In order to calculate the second and further steps the following interpretation could be used. There is a change in the accessible surface due to the coverage by the previous adsorption layer, which is function of original compound concentration, and this area can behave as a new adsorbent surface or it can form new associates. The common features of this theory are an adsorption equilibrium constant $(k)$, an average association degree of the solute $(n)$ and the saturation concentration of the layer $(a)$ in question. The mathematical expression is the same in all cases.

Multi-step isotherms can be calculated additively from the adsorption isotherms of the individual "steps" (Eq.7). Let's call it Czinkota isotherm (Eq. 8).

$$
q=\sum_{i=1}^{s}\left\{\frac{a_{i} \cdot k_{i} \cdot\left[\left(c-b_{i}\right)+a b s\left(c-b_{i}\right)\right]^{n_{i}}}{2^{n_{i}}+k_{i} \cdot\left[\left(c-b_{i}\right)+a b s\left(c-b_{i}\right)\right]^{n_{i}}}\right\}
$$

where $\mathrm{s}$ the total number of steps on isotherms, dimensionless.

The Czinkota isotherm can be used for description of multilayer or associated materials adsorption (Konda et al. 2002, Földényi et al. 2004).

Using the derived function, the parameters of a given isotherm can be calculated by non-linear curve fitting, e.g. least squares method.

Sequential simplex optimization can be used for fitting non-linear models (Walters 1991). It was for this purpose that Nedler (1965) modified the fixed-size simplex of 
Spendley (1962). The factors are the coefficients or parameters in the model and the response is the sum of squares of residuals $\left(\mathrm{SS}_{\mathrm{r}}, \mathrm{Eq} .9\right)$ :

$$
\mathrm{SS}_{\mathrm{r}}=\Sigma\left(\mathrm{y}_{\mathrm{i}, \text { observed }}-\mathrm{y}_{\mathrm{i}, \text { calc }}\right)^{2}
$$

Where $y_{i, c a l c}$ is the value predicted by the model at a given factor combination $i$, $\mathrm{y}_{\mathrm{i}, \text { observed }}$ is the value actually observed, and $\mathrm{n}$ is the number of data points. The object is to find the set of parameter estimates that gives the minimum sum of squares of residuals.

O'Neil (1971) was one of the first to use the simplex algorithm for regression, or model fitting. Caceci (1984) demonstrated how a PASCAL computer program could use the simplex algorithm for curve fitting. A PASCAL algorithm is also given by Press (1989). Jurs (1986) presented a FORTRAN computer program that used simplex for non-linear least squares or regression. The example given used the absorbance data of Deming (1973) and fitted the equation (Eq.10).

$$
\mathrm{A}=\mathrm{A}_{\infty}\left(1-\mathrm{e}^{-\mathrm{kt}}\right)
$$

Modelling adsorption phenomena in soils we use complex nonlinear functions. Sequential simplex optimization can be used to fit: the modelling kinetics of phosphorus adsorption in soils (Füleky 1980), the equilibrium of phosphorus adsorption in soils (Tolner 1987, 1995, 1996; Wahdan 2000, 2000a; Füleky 2006, 2006a), the equilibrium of copper adsorption in soils (Ioannou 2003), the respiration dynamics and microbial transforms in soils (Szegi 1988, Gulyás 1990).

\section{Materials and methods}

In order to establish the sorption isotherms of six commonly used pesticides (acetochlor, atrazine, diazinon, carbendazim, imidacloprid and isoproturon) laboratory equilibrium studies were performed on brown forest soil with clay alluviation (Luvisol) using the batch equilibrium technique. The pesticide concentrations in the equilibrated liquid phase were quantified by high performance liquid chromatograph with UV detection. The sorption isotherms have been described by a new non-linear mathematical model - derived from the modified Langmuir equation - which well represents the single- and multi-step shaped adsorption profile detected for the investigated compounds.

\section{Results}

We derived a non-linear mathematical model - obtained from geometric series of modified Langmuir equation with the additional assumption that the actual location of the surface sites are covered either by one or more than one molecule, in form of associated complex. Such complexes may be formed, e.g. by dispersion forces acting between the hydrophobic surfaces of the dissolved molecules. We assume formation of layers of associated complexes of different composition characterized by the association number $(n)$, beginning with a single layer of the solute, continued with the layer of dimers $(n=2)$, trimers $(n=3)$ etc. The physicochemical interpretation of the theory is detailed in the Introduction according to Czinkota et al. (2002). To provide a physically sound interpretation consistent with the adsorption theory described in the literature, the following assumptions should be made: (1) the adsorption area of any kind of associated complexes, regardless of association number, should not differ significantly; (2) the distance of the active sites of adsorption on the surface should be greater than the size of 
any kind of associated complexes; (3) molecular interactions acting during adsorption and formation of associated complexes should involve different parts of the molecules, which means that adsorption and formation of associations are independent processes; (4) formation of associated complexes is considered irreversible thus their dissociation is not discussed here.

The mathematical equation detailed above (Eq. 8) has been applied to describe adsorption isotherms for all the examined compounds. We found that the experimental adsorption data could be simulated with single-step (Langmuir) model for acetochlor and carbendazim, two-step (Czinkota) model for diazinon, isoproturon, and atrazine, and three step (Czinkota) model for imidacloprid.

The three steps isotherm is presented in Eq. 11:

$q=\frac{a_{1} \cdot k_{1} \cdot c}{1+k_{1} \cdot c}+\frac{a_{2} \cdot k_{2} \cdot\left[\left(c-b_{2}\right)+a b s\left(c-b_{2}\right)\right]^{2}}{4+k_{2} \cdot\left[\left(c-b_{2}\right)+a b s\left(c-b_{2}\right)\right]^{2}}+\frac{a_{3} \cdot k_{3} \cdot\left[\left(c-b_{3}\right)+a b s\left(c-b_{3}\right)\right]^{3}}{8+k_{3} \cdot\left[\left(c-b_{3}\right)+a b s\left(c-b_{3}\right)\right]^{3}}$

The fitted adsorption isotherm of imidacloprid on soil can be seen in Fig. 1.

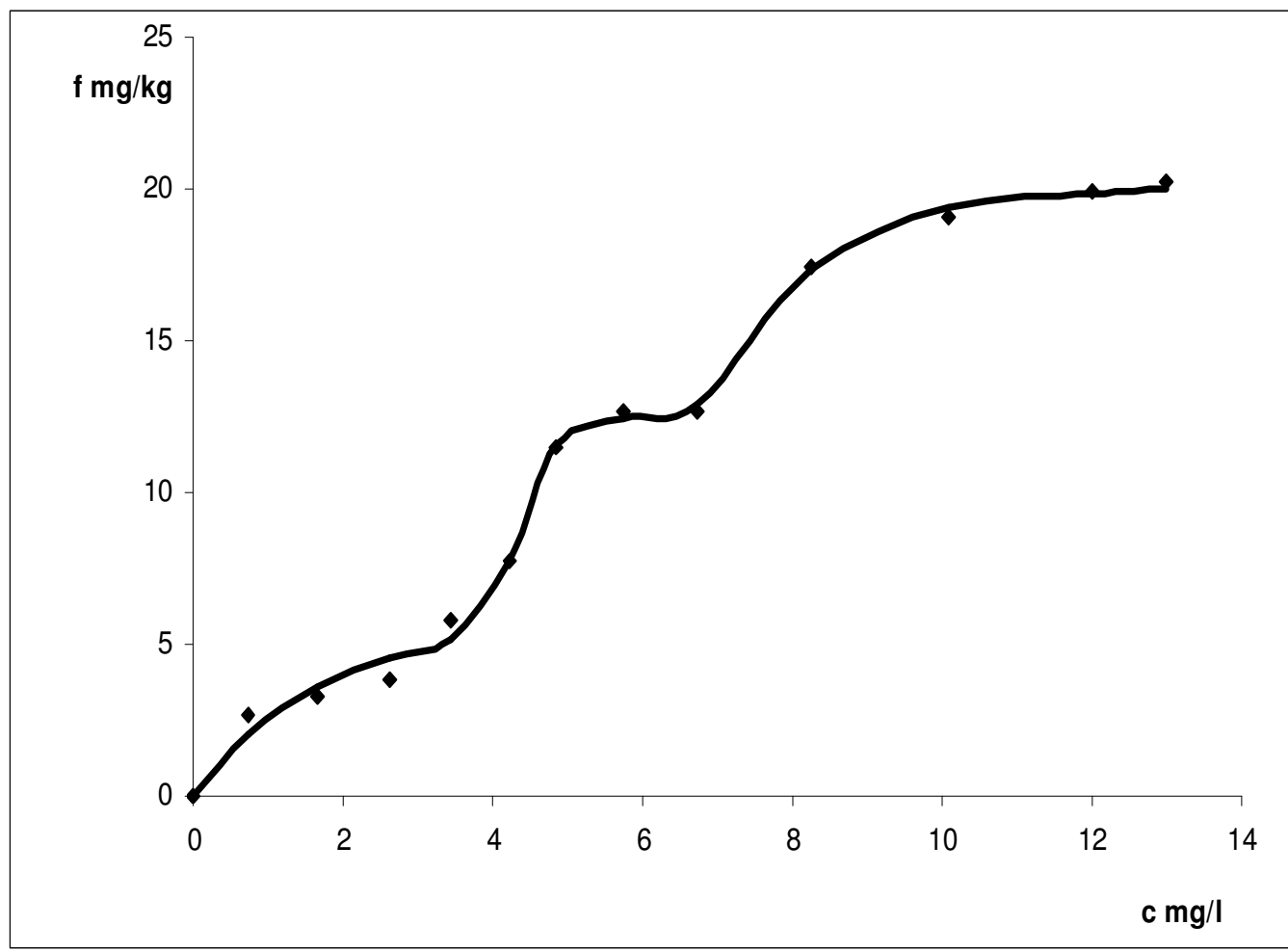

Figure 1. Adsorption of imidacloprid on brown forest soil. Points measured: the adsorbed imidacloprid in function of the equilibrium concentration. Continuous line: the fitted three-step isotherm.

The model parameters $\left(a_{1}, k_{1}, a_{2}, k_{2}, b_{2}, a_{3}, k_{3}, b_{3}\right)$ were determined by non-linear regression using sequential simplex optimization. Excel macro function was written in Visual Basic program language, and it was used as a fitting program.

The algorithm of non-linear regression calculation using sequential simplex optimization is interpreted here by means of the example of a two-parameter function 
fitting (Eq. 12). As it is a two dimensional problem, it can be drawn in approximately two dimensional graph (the third dimension are the colours or level lines) (Fig. 2).

$$
q=\frac{A \cdot k \cdot c}{1+k \cdot c}
$$

The measured data pairs are the equilibrium concentration $(c)$ and the specific adsorbed amount $(q)$. Parameters " $A$ " and " $k$ " will be determined by regression by the following method: the residual sum of squares between measured and calculated values $\left(\mathrm{SS}_{\mathrm{r}}\right.$, as it is presented in Eq. 13) should be minimal in the given range (cf. Eq.9).

$$
\mathrm{SS}_{\mathrm{r}}=\Sigma\left(\mathrm{q}_{\mathrm{i}, \text { observed }}-\mathrm{q}_{\mathrm{i}, \text { calc }}\right)^{2}
$$

$\mathrm{SS}_{\mathrm{r}}$ is shown in function of " $A$ " and " $k$ " leading to the figure with line of levels (see Fig. 2).

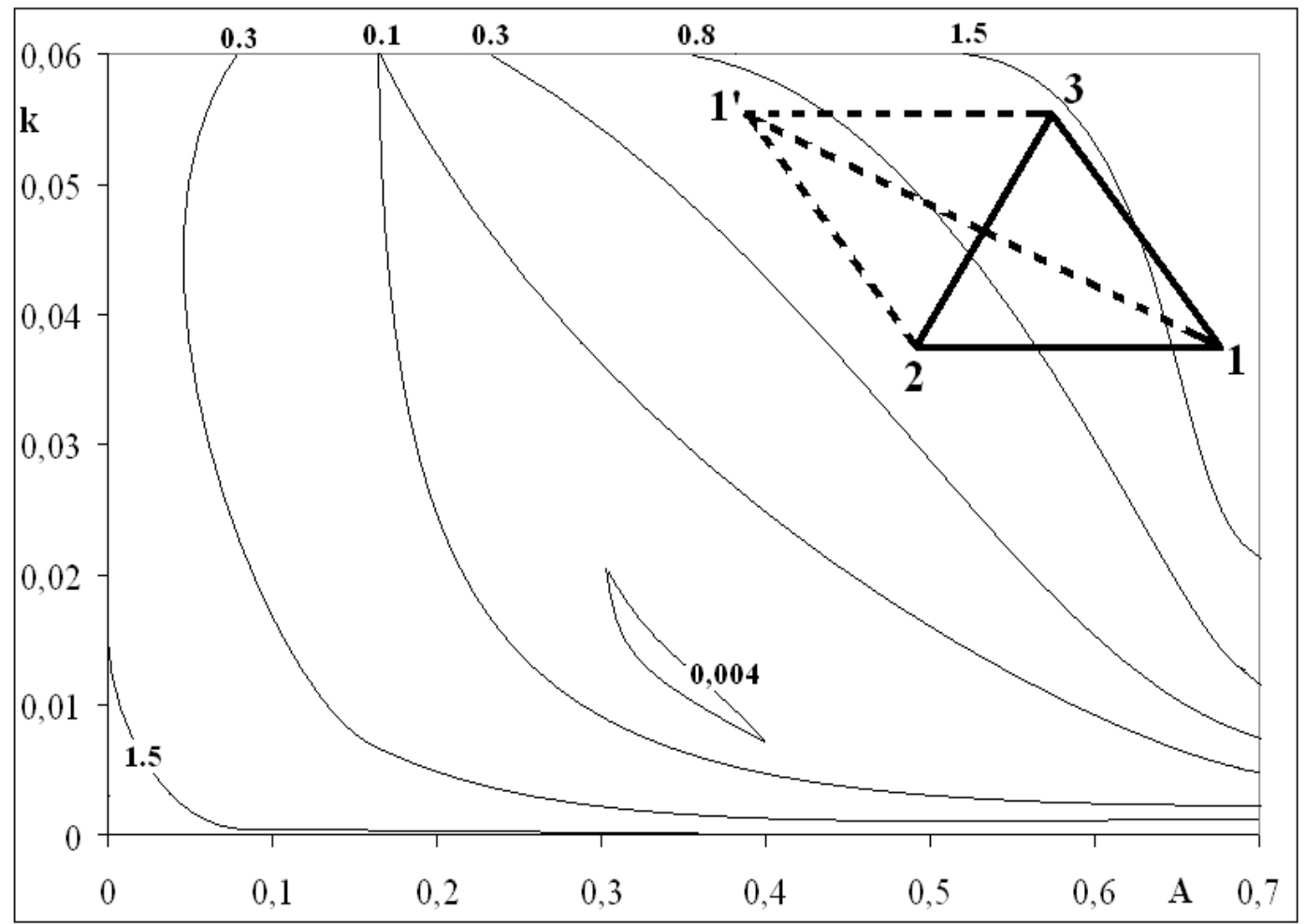

Figure 2. Sequential Simplex optimization in order to determine the parameters $(A, k)$. 1. step.

During the calculation the $A$ and $k$ values were determined by using the given 1,2 and 3 marked points, and $\mathrm{SS}_{\mathrm{r}}$ values were calculated. Then the point having the highest $\mathrm{SS}_{\mathrm{r}}$ value was chosen, where the fitting is the least suitable. In our example this is the point 1 . Mirroring this point on the half point of the line determined by the other two points, we can create the 1' point. The use of this point in a new calculation usually results in better fitting so we get less $\mathrm{SS}_{\mathrm{r}}$ value. Repeating this routine the optimum can be reached (Fig. 3.). 


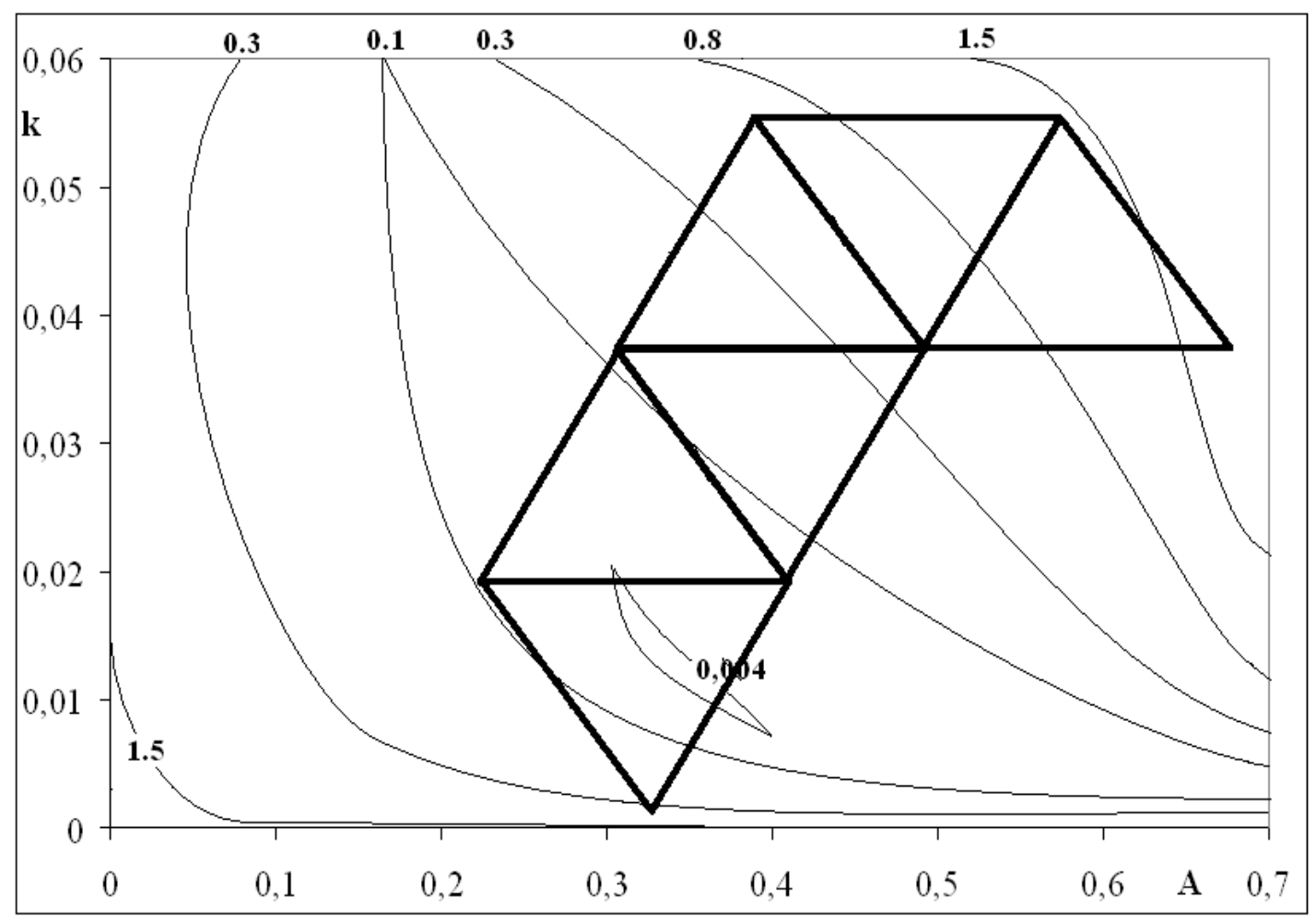

Figure 3. Sequential Simplex optimization in order to determine the parameters $(A, k) .5$ step.

In order to approach the optimum more exactly this procedure can be continued by decreasing the size of simplex (in this case triangle).

When this procedure is applied to Czinkota isotherm in the case of imidaclopride adsorption, the values shown in Table 1 were calculated.

Table 1. Parameters and Variance table of Czinkota ishotherm for imidaclopride adsorption

$\begin{array}{cccccccc}\boldsymbol{a}_{1} & \boldsymbol{k}_{1} & \boldsymbol{a}_{2} & \boldsymbol{k}_{2} & \boldsymbol{b}_{2} & \boldsymbol{a}_{3} & \boldsymbol{k}_{3} & \boldsymbol{b}_{3} \\ 5,563 & 1,007 & 9,6269 & 0,45266 & 2,91358 & 5,34216 & 1,16231 & 7,09005 \\ & & & & & & \\ & & & & & & & \\ & \text { Variance table } & \text { SS } & \text { DF } & \text { MS } & \text { F } & \mathbf{R}^{2} \\ & \text { Total } & 612,7557 & 12 & & & \\ & \text { Regression } & 611,1635 & 7 & 87,309 & 274,2 & 0,9974 \\ & \text { Residual } & 1,5921 & 5 & 0,3184 & & \end{array}$

\section{Discussion}

The sorption isotherms have been described by a new non-linear mathematical model derived from the modified Langmuir equation. It well represents the single- and multistep shaped adsorption profile experienced in the case of the investigated compounds. The experimental adsorption data were well fitted by the proposed model. The physicochemical interpretation of the mathematical formula has been derived from chemical equilibrium consideration. The interpreted model allows the description of the 
adsorption profile with great precision. The parameters calculated by means of the new equation provide an opportunity to estimate the extent of adsorption constant, adsorption capacity and concentration limit being characteristic to the measured stepwise isotherm in the studied soil-pesticide environmental system.

Acknowledgements. The financial support of Hungarian Scientific Research Foundation under grant No. T 32506 is gratefully acknowledged.

\section{REFERENCES}

[1] Adamson, A. W. (1990): Physical Chemistry of Surfaces - Wiley Interscience, New York

[2] Brunauer, S., Emmett, P. H., Teller, E. (1938): Adsorption of gases in multimolecular layers. - J. Am. Chem. Soc. 60: 309-319.

[3] Caceci, M. S., Cacheris, W. R. (1984): Fitting curves to data. - Byte, 340-362.

[4] Czinkota, I., Földényi, R., Lengyel, Zs., Marton, A. (2002): Adsorption of propisochlor of soils and components equation for multi-step isotherms. - Chemosphere 48: 725-731

[5] Deming, S. N., Morgan, S. L. (1973): Simplex optimization of variables in analytical chemistry. - Anal. Chem. 45(3): 278A-283A.

[6] Földényi, R., Czinkota, I., Ertli, T. (2004): Presentation of multi-step isotherms formed at the adsorption of herbicides. Progress in Colloid and Polymer Science 125: 117-120.

[7] Füleky, Gy., Tolner, L., Dömsödi, J. (1980): Kinetics of phosphorus supply measured by anion exchange reson. [A talaj foszforszolgáltatása kinetikájának mérése anioncserélő mügyantával.] - Agrokémia és Talajtan 29: 273-280.

[8] Füleky, Gy., Tolner, L., Wahdan, A. (2006): Effect of acidification on recovery of fertilizer phosphorus with three water extraction methods. - Cereal Research Communications, 34: 183-186.

[9] Füleky, Gy., Tolner, L. (2006a): Determination of the phosphate content originally adsorbed on the soil by fitting an adsorption isotherm model. - Applied Ecology and Environmental Research, 4(2): 39-45.

[10] Greg, S. J., Sing, K. S. W. (1982): Adsorption, surface area and porosity - Academic Press, New York.

[11] Gulyás, F., Szili-Kováts, T., Szegi, J., Füleky, Gy., Tolner, L. (1990): Effect of NPK Fertilization and Organic Matter on the Respiration Dynamics and Microbial N Transformation Processes of the Soil. - Agrokémia és Talajtan 39. 423-429.

[12] Ioannou, A. Tolner, L., Dimirkou, A., Füleky, Gy. (2003): Copper adsorption on bentonite and soil as affected by $\mathrm{pH}$. - Bulletin of the Szent István University, Gödöllö, 74-84.

[13] Jurs, P. C. (1986): Computer Software Applications in Chemistry. - John Wiley, New York, Chapter 9, pp. 125-140.

[14] Konda, L. N., Czinkota, I., Fuleky, G., Morovjan, G. (2002). Modeling of single-step and multistep adsorption isotherms of organic pesticides on soil. - Journal of Agricultural and Food Chemistry 50:7326-7331.

[15] Langmuir, I. (1918): The adsorption of gases on plane surfaces of glass, mica and platinum. - J. Am. Chem. Soc. 40: 1362-1403.

[16] Nelder, A., Mead, R. (1965): A simplex method for function minimization. - Comput. J. 7: 308-313.

[17] O'Neil, R. (1971): Function minimization using a simplex procedure. - Appl. Stat. 20: 338-345.

[18] Press, B. P., Flannery, B. P., Teukolsky, S. A. Wetterline, W. T. (1989): Numerical Recipies in Pascal. The Art of Scientific Computing, - Cambridge University Press, Cambridge. 
[19] Ruthven, D. M. (1984): Principles of adsorption and adsorption processes. - Wiley Interscience, New York

[20] Rudzinski, W.; Everett, D. H. (1992): Adsorption of gases on heterogeneous surfaces. Academic Press, London

[21] Sparks, D. L. (Ed.) (1999): Kinetics and Mechanisms of Chemical Reactions at the Soil Mineral/Water Interface in Soil Physical Chemistry. - 2nd Edition, Chapter 4, pp. 135191, CRC Press

[22] Sparks, D. L., Scott, E., Fendorf, Peng-Chu, Zhang; Liya, Tang (1993): Kinetics and Mechanisms of Environmentally Important Reactions on Soil Colloidal Surface in Migration and Fate of pollutans in Soils and Subsoils - NATO ASI Series, Vol. G 32, Springer-Verlag, 141-168.

[23] Spendley, W., Hext, G. R., Himsworth, F. R. (1962): Sequential application of simplex designs in optimisation an evolutionary operation. - Technometrics 4: 441-461.

[24] Sposito, G. (1984): The Surface Chemistry of Soil. - Oxford Univ. Press, New York

[25] Szegi, J., Gulyás, F., Füleky, Gy., Tolner, L. (1988): Influence of NPK fertilization and cellulose application on the CO2 production of soils. - Ztbl. Mikrobiol., 143: 303-308.

[26] Tolner, L. Füleky, Gy. (1987): Availability of soil phosphorus by anion exchange resin. Bull. of the Univ. of Agric. Sci. Gödöllö 1: 121-132.

[27] Tolner, L., Füleky, Gy. (1995): Determination of the Originally Adsorbed Soil Phosphorus by Modified Freundlich Isotherm. - Commun. Soil Sci. Plant Anal. 26: 12131231.

[28] Tolner, L., Wahdan, A., Füleky, Gy. (1996): A talajban adszorbeálódott foszfáttartalom többlépéses deszorpciójának modellezése. - Agrokémia és Talajtan 45: 295-306.

[29] Walters, Parker, Morgan, Deming (1991): Sequential Simplex Optimization. - CRC Press LLC, Florida.

[30] Wahdan, A., Füleky, Gy., Tolner, L. (2000): Recovery of sorbed fertilizer phosphorus by three water extraction methods. - Bulletin of the Szent István University. 1997-2000: Gödöllo, pp.75-81.

[31] Wahdan, A., Füleky, Gy., Tolner, L. (2000a): Phosphate sorption capacity of a calcareus soil influenced by acidification. - Bulletin of the Szent István University. 1997-2000: Gödöllo, pp.83-91.

[32] Yang, R. T. (1987): Gas separation by adsorption processes. - Butterworth Publishers, Boston 